\title{
Chromosomal Locations of Microsatellites in Onion
}

\author{
Shinichi Masuzaki \\ The United Graduate School of Agricultural Sciences, Tottori University, \\ Tottori 680-8553, Japan
}

Naoyuki Araki

Forensic Science Laboratory, Yamaguchi Prefectural Police Headquarters, Yamaguchi 753-8504, Japan

\section{Naoki Yamauchi}

The United Graduate School of Agricultural Sciences, Tottori University, Tottori 680-8553, JAPAN and Department of Biological and Environmental Science, Faculty of Agriculture, Yamaguchi University, Yamaguchi 753-8515, Japan

\section{Naoko Yamane \\ Department of Biological and Environmental Science, Faculty of Agriculture, Yamaguchi University, Yamaguchi 753-8515, Japan}

\section{Tadayuki Wako and Akio Kojima \\ National Institute of Vegetable and Tea Science, National Agricultural Research Organization, Mie 514-2392, Japan}

\section{Masayoshi Shigyo ${ }^{1}$ \\ The United Graduate School of Agricultural Sciences, Tottori University, Tottori 680-8553, JAPAN and Department of Biological and Environmental Science, Faculty of Agriculture, Yamaguchi University, Yamaguchi 753-8515, Japan \\ Additional index words. Allium cepa, Allium fistulosum, chromosomal location, microsatellite, monosomic addition line}

\begin{abstract}
Bulb onion (Allium cepa $\mathbf{L}$.) has a very large genome composed of a high proportion of repetitive DNAs. Genetic analyses of repetitive sequences may reveal microsatellites in order to increase the number of genetic markers in onion. Thirty microsatellites were previously isolated from an onion genomic library (Fischer and Bachmann, 2000). A complete set of Japanese bunching onion (A. fistulosum) - shallot (A. cepa Aggregatum group) monosomic addition lines were used to assign these microsatellites to the chromosomes of $A$. cepa. Simplified PCR conditions for each microsatellite were determined and 28 of the 30 primer pairs amplified DNA fragments, of which 21 microsatellite markers were assigned to chromosomes of $A$. cepa. Subsequent mapping of these microsatellites will enable us to establish the chromosomal distribution of these markers.
\end{abstract}

Microsatellites, or simple sequence repeats (SSRs), are tandemly repeated motifs of one to a few nucleotides (Field and Wills, 1996; Tautz and Renz, 1984) and are present at both protein-coding and noncoding regions of the genome (Toth et al., 2000). Microsatellites are highly polymorphic among individuals of a population (Morgante and Olivieri, 1993; Tautz, 1989). Polymorphism may be caused by slippage events during DNA replication (Schlötterer and Tautz, 1992). The information content among molecular markers is high for microsatellite markers due to intraspecific polymorphism, co-dominance, and high reliability and reproducibility (Bohn et al., 1999; Jones et al., 1997; Powell et al., 1996; Russell et al., 1997). Microsatellite markers have been used

Received for publication 1 Dec. 2005. Accepted for publication 29 Dec. 2005. We are grateful to Toyoshi Iwata, Shippo Seed Co., LTD., Kagawa, Japan, for providing financial support for this study.

${ }^{1}$ Corresponding author; e-mail shigyo@yamaguchiu.ac.jp. for the construction of genetic maps (Barrett et al., 2004; Blair et al., 2003; Cregan et al., 1999; Röder et al., 1998; Somers et al., 2004) and are useful for plant breeding (Gupta and Varshney, 2000).

There have been few reports of microsatellites in the genus Allium. Fischer and Bachmann (1998) were the first to report microsatellites from onion (A. cepa L. Common onion group) and developed 30 primer pairs flanking microsatellite motifs to assess interspecific taxonomic analyses in Allium (Fischer and Bachmann, 2000). Because of the intricate PCR conditions required to reveal these microsatellites, including touch-down PCR and the use of fluorescein-labeled primers, it is difficult for a small laboratory to score these microsatellites.

The objectives of the present study were 1) to simplify the PCR conditions for $30 \mathrm{mi}-$ crosatellites developed by Fischer and Bachmann (2000) and 2) to assign microsatellite markers to the chromosomes of shallot ( $A$. cepa L. Aggregatum group) by using the $A$. fistulosum-shallot monosomic addition lines (Shigyo et al., 1996).

\section{Materials and Methods}

Plant materials. Two complete sets of A. fistulosum-shallot monosomic additions (Shigyo et al., 1996) were used to assign microsatellite markers to the chromosomes of shallot. The sets were analyzed together with their parents: shallot (A. cepa L. Aggregatum group) and Japanese bunching onion ( $A$. fistulosum L. 'Kujo Hoso'). Shallot was used to determine the PCR conditions for each of 30 primer pairs (AMS01 to AMS30; GenBank accession numbers, AJ391666 to AJ391725) described by Fischer and Bachmann (2000). Total genomic DNA was isolated from fresh leaf tissue using a mini-prep DNA-isolation method (van Heusden et al., 2000a).

Simplification of PCR conditions for 30 primer pairs. Polymerase chain reactions (PCRs) were performed with the 30 primer pairs in a program thermal cycler (iCycler; Bio-Rad, Hercules, Calif.) to simplify the complicated touch-down PCRs reported by Fischer and Bachmann (2000). Two conditions for simplification were as follows; PCR mixture I was made with $0.4 \mu \mathrm{M}$ of each of the primers, 0.1 mM dNTPs, $1 \times$ rTaq buffer, 1 U rTaq polymerase(Takara, Shiga, Japan), and $100 \mathrm{ng}$ template DNA in a volume of $25 \mu \mathrm{L}$; mixture II differed in that $1 \times$ PCR Gold buffer and 1.25 U AmpliTaq Gold (Applied Biosystems, Foster City, Calif.) were used instead of $1 \times$ rTaq buffer and $1 \mathrm{U}$ rTaq polymerase, and that additional $1 \mathrm{~mm}$ magnesium were used. PCR temperatures were as follows: $94{ }^{\circ} \mathrm{C}(3 \mathrm{~min})$ followed by 35 cycles at $94{ }^{\circ} \mathrm{C}(30 \mathrm{~s}), 50$ to $60{ }^{\circ} \mathrm{C}(1 \mathrm{~min})$, and $72{ }^{\circ} \mathrm{C}(1 \mathrm{~min})$, with a final extension at $72{ }^{\circ} \mathrm{C}$ for $7 \mathrm{~min}$ for the mixture I. For the mixture II, the sequence was $95^{\circ} \mathrm{C}$ (11 min) followed by 40 cycles at $94{ }^{\circ} \mathrm{C}(30$ s), 50 to $60{ }^{\circ} \mathrm{C}(30 \mathrm{~s})$, and $72{ }^{\circ} \mathrm{C}(30 \mathrm{~s})$, with a final extension at $72{ }^{\circ} \mathrm{C}$ for $10 \mathrm{~min}$. The ramp times were carried out in the default conditions that adjusted temperatures at the maximum ramp rate with the minimum ramp time. The PCR products were separated on $2.0 \%$ agarose gel. The optimum annealing temperature for each primer pair was chosen after production of fewer nonspecific amplicons.

Assignment of microsatellite markers to chromosomes. The primer pairs with simplified PCR conditions were analyzed for shallot-specific amplicons between A. fistulosum and shallot. If products were monomorphic, they were subjected to denaturing polyacrylamide gel electrophoresis (PAGE) with silver staining. If they were also monomorphic after denaturing PAGE, they were subjected to capillary electrophoresis with an ABI PRISM 310 Genetic Analyzer (Applied Biosystems). Simple polymorphic amplicons were analyzed with denaturing PAGE or SSCP analysis using electrophoresis and gel with silver staining. Denaturing PAGE and SSCP were performed as described by Martin et al. (2005). PCR for capillary electrophoresis was performed with one $5^{\prime}$ fluorescent-labeled primers (NED for AMS01, 


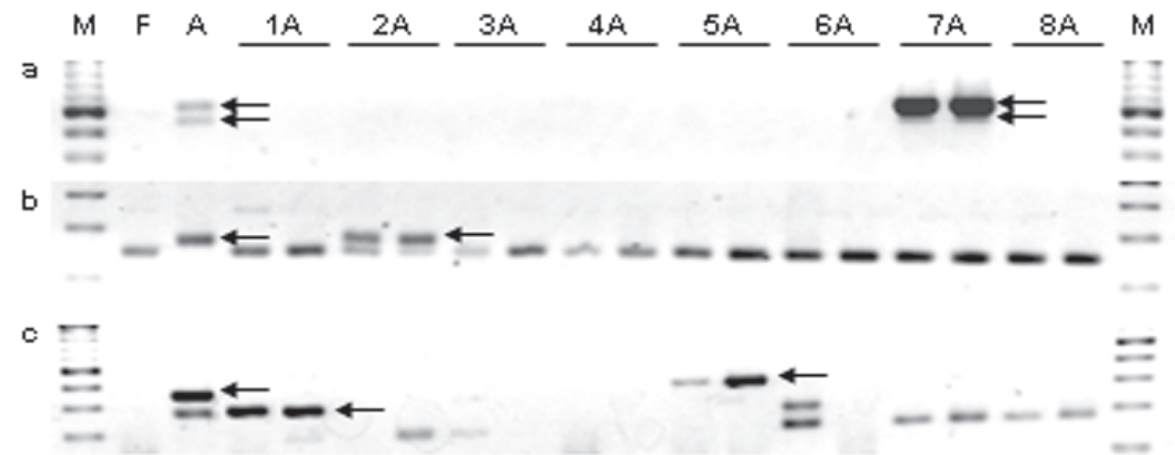

Fig. 1. Amplification profiles for the primer pairs, AMS02 (a), AMS14 (b) and AMS17 (c), in A. fistulosum (F), shallot (A), and the two sets of A. fistulosum-shallot monosomic additions (1A to 8A) on agarose gel. M, molecular size marker. Arrows point to shallot chromosome specific markers. (a) AMS02-470 and AMS02-530 located on chromosome 7A; (b) AMS14-175 located on 2A; (c) AMS17-270 located on 1A and AMS17-360 located on 5A.

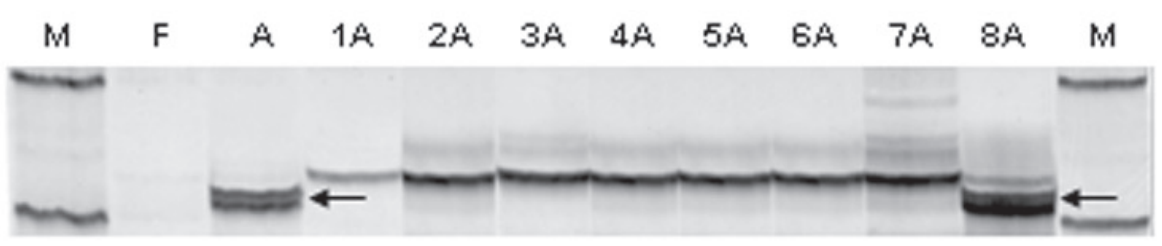

Fig. 2. Part of amplification profiles for the primer pair AMS29 in A. fistulosum (F), shallot (A), and the set of A. fistulosum-shallot monosomic additions (1A to 8A) on denaturing polyacrylamide gel. M, molecular size marker. Arrows indicate chromosome $8 \mathrm{~A}$ specific marker.

FAM for AMS05 and HEX for AMS24) using $15 \mu \mathrm{l}$ sample containing $1 \mathrm{pM}$ fluorescent-

labeled primer, $1 \mu \mathrm{M}$ reverse primer, $0.2 \mathrm{~mm}$ dNTPs, 0.125 U AmpliTaq Gold, and 100 ng template DNA in $1 \times$ Gold buffer with $4 \mathrm{mM}$ magnesium. PCR amplification was carried out for 35 cycles, 30 -s denaturation at $94{ }^{\circ} \mathrm{C}$; 30 -s annealing at 56 to $60^{\circ} \mathrm{C}$; and 30 -s primer extension at $72{ }^{\circ} \mathrm{C}$. PCR was preceded by 11 min of pre-denaturation at $94^{\circ} \mathrm{C}$ and followed by 10 min of postsynthesis at $72^{\circ} \mathrm{C}$. The analysis with the ABI PRISM 310 and subsequent analyses were conducted using a modification of the procedure of Araki et al. (2003). The amplified fragments from 100 to $700 \mathrm{bp}$ were scored in each A. fistulosum and shallot. The primer pairs producing shallot-specific bands were used to assign chromosomal locations using the monosomic additions. The markers were designated according to the primer name and the molecular size of each band in base pairs.

\section{Results}

Simplification of PCR conditions. The PCR conditions for shallot were simplified for 28 primer pairs (Table 1). Amplicons of approximately the same sizes as reported by Fischer and Bachmann (2000), were observed for 19 primer pairs. Nine primer pairs amplified amplicons of different sizes from onion and shallot, and two primer pairs of AMS11 and AMS15 amplified no PCR products in shallot under all the PCR conditions. We simplified the PCR conditions for 21 of 22 primer pairs with the exception of AMS11. The optimum

Table 1. Simplified PCR conditions, electrophoresis for polymorphism detection, and fragment sizes amplified from A. fistulosum and shallot.

\begin{tabular}{|c|c|c|c|c|c|c|}
\hline Microsatellite ${ }^{z}$ & $\begin{array}{l}\text { PCR } \\
\text { mixture }\end{array}$ & $\begin{array}{l}\text { Annealing } \\
\text { temp }\left({ }^{\circ} \mathrm{C}\right)\end{array}$ & Electrophoresis ${ }^{y}$ & $\begin{array}{l}\text { Expected } \\
\text { size }(b p)^{x}\end{array}$ & $\begin{array}{l}\text { Observed size } \\
\text { (bp) in shallot }{ }^{\mathrm{w}}\end{array}$ & $\begin{array}{l}\text { Observed size } \\
\text { (bp) in A. fistulosum }{ }^{\mathrm{w}}\end{array}$ \\
\hline AMS02 & I & 54.0 & A & 530 & 470,530 & --- \\
\hline AMS03 & II & 56.0 & $\mathrm{P}$ & 121 & 203,242 & $127,197,228,271,342$ \\
\hline AMS05 & II & 56.0 & $\mathrm{C}$ & 229 & $\begin{array}{l}117,127,135,140,147,152,155,162, \\
207,214,354,365\end{array}$ & $101,102,118,135,159,355$ \\
\hline AMS06 & I & 55.0 & $\mathrm{P}$ & 147 & 105 & 149 \\
\hline AMS09 & I & 54.2 & $\mathrm{P}$ & 278 & 236,278 & 236 \\
\hline AMS10 & II & 52.9 & $\mathrm{P}$ & 157 & $150,255,285$ & 255 \\
\hline $\operatorname{AMS11}^{\mathrm{v}}$ & --- & --- & --- & 92 & --- & --- \\
\hline AMS12 & II & 56.0 & $\mathrm{P}$ & 274 & 237,274 & --- \\
\hline AMS13 & I & 58.0 & $\mathrm{P}$ & 168 & 138 & 139 \\
\hline AMS14 & II & 60.0 & A & 169 & 175 & 157 \\
\hline AMS15 & II & 58.0 & $\mathrm{P}$ & 229 & --- & $122,187,211,261,529$ \\
\hline AMS21 & I & 56.0 & $\mathrm{P}$ & 264 & $141,194,220,235,250$ & 235,250 \\
\hline AMS22 & II & 57.4 & $\mathrm{P}$ & 310 & $270,282,310,330,360$ & 282,360 \\
\hline AMS23 & II & 58.0 & A & 157 & 150,218 & 135 \\
\hline AMS24 & II & 57.4 & $\mathrm{C}$ & 161 & $\begin{array}{l}111,125,127,133,142,147,151,153 \\
155,173,197,210,220\end{array}$ & $138,144,145,238,265$ \\
\hline AMS25 & I & 52.5 & $\mathrm{P}$ & 235 & 200,220 & 200,210 \\
\hline AMS26 & I & 52.5 & $\mathrm{P}$ & 213 & 206,225 & --- \\
\hline AMS27 & II & 54.0 & $\mathrm{~S}$ & 318 & $177,235,338,390,430,550$ & $235,288,430,550$ \\
\hline AMS28 & II & 58.0 & $\mathrm{P}$ & 250 & 150,242 & $150,230,362,571$ \\
\hline AMS29 & I & 54.0 & $\mathrm{P}$ & 310 & 315 & 332 \\
\hline AMS30 & II & 57.4 & $\mathrm{P}$ & 342 & 342 & --- \\
\hline
\end{tabular}

${ }^{z}$ The STMS numbers were described by Fischer and Bachmann (2000).

${ }^{\mathrm{y}} \mathrm{A}, \mathrm{P}, \mathrm{C}$, and $\mathrm{S}$ indicate agarose gels, denaturing polyacrylamide gels, capillary and SSCP, respectively.

${ }^{x}$ Expected size in each microsatellite is the fragment size in onion that Fischer and Bachmann (2000) mentioned.

wThe observed size in A. fistulosum and shallot in AMS27 shows the fragments detected on denaturing PAGE.

'The primer pair of AMS11 amplified no DNA fragment in A. fistulosum and shallot under all the conditions used in this study. 
Table 2. Chromosomal locations of microsatellite markers in shallot.

\begin{tabular}{|c|c|}
\hline Chromosome & Microsatellite marker \\
\hline \multirow[t]{4}{*}{$1 \mathrm{~A}$} & AMS01-113 \\
\hline & AMS09-278z \\
\hline & AMS16-261 \\
\hline & AMS17-270 \\
\hline \multirow[t]{4}{*}{$2 \mathrm{~A}$} & AMS08-190 \\
\hline & AMS $10-150^{z}$ \\
\hline & AMS14-175 \\
\hline & AMS27-390 \\
\hline \multirow[t]{2}{*}{$3 \mathrm{~A}$} & AMS12-274 \\
\hline & AMS23-218 \\
\hline \multirow[t]{3}{*}{$4 \mathrm{~A}$} & AMS01-127z \\
\hline & AMS20-372 \\
\hline & AMS23-150 \\
\hline \multirow[t]{2}{*}{$5 \mathrm{~A}$} & AMS17-360 \\
\hline & AMS21-141 \\
\hline \multirow[t]{2}{*}{$6 \mathrm{~A}$} & AMS09-278z \\
\hline & AMS21-141 z \\
\hline \multirow[t]{5}{*}{$7 \mathrm{~A}$} & AMS01-113 \\
\hline & AMS02-470 \\
\hline & AMS02-530 \\
\hline & AMS12-237 \\
\hline & AMS24-210 \\
\hline \multirow[t]{4}{*}{$8 \mathrm{~A}$} & AMS01-127z \\
\hline & AMS $10-150^{z}$ \\
\hline & AMS26-225 \\
\hline & AMS29-315 \\
\hline
\end{tabular}

$\overline{\text { zThe footnotes show the markers located on the two }}$ chromosomes.

annealing temperature differences between onion (Fischer and Bachmann, 2000) and shallot (these results) varied from -17.4 to $1.3{ }^{\circ} \mathrm{C}$.

Polymorphisms between A. fistulosum and shallot. The 28 primer pairs revealed polymorphic amplicons between $A$. fisulosum and shallot, and of which two for AMS02, one for AMS14, two for AMS17, and two for AMS23 were obtained (Table 1; Fig. 1). For 16 primer pairs out of the remaining 24 , a total of 27 shallot-specific bands were detected on denaturing PAGE with silver staining (Table 1; Fig. 2). Three primer pairs (AMS01, AMS05, and AMS24) showed complex amplification products after denaturing PAGE were subjected to capillary electrophoresis yielding 6,11 , and 13 shallot-specific bands, respectively (Table 1). Nine primer pairs that were monomorphic between $A$. fistulosum and shallot using denaturing PAGE were analyzed using SSCP with silver staining, and one shallot-specific band was detected only for AMS27 (data not shown). In total, 65 amplicons specific to shallot were observed for 24 out of the 28 primer pairs (Table 1).

Chromosomal locations of microsatellite markers. The 65 amplicons were assigned to shallot chromosomes. Twenty-one out of the 65 shallot-specific amplicons were detected in a single monosomic addition or two additions (Figs. 1 and 2). The microsatellite marker AMS14-175 was detected in monosomic additions with chromosome $2 \mathrm{~A}$ but not in any other monosomic additions (Fig. 1b). In the same way, the chromosomal locations of the remaining 20 markers were revealed (Table 2; Figs. 1 and 2). Of the 21 chromosome-specific markers, 16 were located on single chromosomes, and the other five primers produced amplicons located on two chromosomes each. Seven markers, i.e., AMS01-113, AMS02-
470, AMS12-237, AMS17-360, AMS21-141, AMS23-218 and AMS24-210, did not correspond with the amplicon size in onion reported by Fischer and Bachmann (2000). These seven markers produced additional amplicons of different sizes to those reported by Fischer and Bachmann (2000). Of the 44 amplicons not assigned to shallot chromosomes, 23 were absent from all monosomic additions, and 21 were detected in three or more additions (data not shown).

\section{Discussion}

We produced 65 amplicons from shallot carrying microsatellites (Table 1) and assigned 21 amplicons to shallot chromosomes (Table 2). Linkage maps of onions have been produced based on AFLPs (van Heusden et al., 2000a, 2000b), and SSRs, SNPs, RAPDs and RFLPs (King et al., 1998; Martin et al., 2005). These two maps may be expanded by the 65 microsatellite amplicons obtained in this study. Of 14 linkage groups of the RFLP map, 12 have been assigned to chromosomes using the $A$. fistulosum-shallot monosomic addition set (Martin et al., 2005). The remaining two unassigned linkage groups might be assigned to chromosomes using 21 chromosome-specific microsatellite markers. Assigning markers to the physical chromosomes of $A$. cepa by linkage mapping is still difficult because of lack of mapping stocks and high levels of heterozygosity. This means that assignment of polymorphic markers to specific chromosomes via our monosomic additions provide a very useful set of genetically characterized markers for application in A. cepa. The appearance of more than two amplicons in diploid shallot means that the locus must be duplicated. Of 28 primer pairs, 18 produced one or two amplicons and the results represent high frequency of single locus PCR markers by comparison with $23 \%$ duplication rate in onion described by King et al. (1998).

Song et al. (2004) reported the isolation of microsatellites with dinucleotide motifs from Japanese bunching onion (A. fistulosum L. 'Kujo Futo') and the suitability of microsatellite markers for genetic analysis in bunching onion. This is the only report of microsatellites in A. fistulosum. In this study, 23 out of 30 primer pairs amplified DNA fragments both in shallot and $A$. fistulosum indicating that the 23 primer pairs may be useful for genetic analysis of A. fistulosum (Table 1). In addition, we obtained 45 microsatellite amplicons specific to $A$. fistulosum for 19 out of 23 primer pairs. Eight shallot $-A$. fistulosum monosomic additions $(2 n=2 x+1=17)$ and 20 shallot $-A$. fistulosum single alien deletions $(2 n=3 x-1$ $=23$ ) have been produced (Hang et al., 2004) and it will be possible to assign these $45 \mathrm{mi}$ crosatellite amplicons to the chromosomes of A. fistulosum.

\section{Literature Cited}

Araki, N., T. Furuta, T. Ohara, N. Yamauchi, and M. Shigyo. 2003. Cultivar discrimination among wakegi onion (Allium $\times$ wakegi Araki) by fluorescent AFLP technique. J. Jpn. Soc. Hort. Sci.
$72: 230-235$

Barrett, B., A. Griffiths, M. Schreiber, N. Ellison, C. Mercer, J. Bouton, B. Ong, J. Forster, T. Sawbridge, G. Spangenberg, G. Bryan, and D. Woodfield. 2004. A microsatellite map of white clover. Theor. Appl. Genet. 109:596-608.

Blair, M.W., F. Pedraza, H.F. Buendia, E. GaitanSolis, S.E. Beebe, P. Gepts, and J. Tohme. 2003. Development of a genome-wide anchored microsatellite map for common bean (Phaseolus vulgaris L.). Theor. Appl. Genet. 107:1362-1374.

Bohn, M., H.F. Utz, and A.E. Melchinger. 1999. Genetic similarities among winter wheat cultivars determined on the basis of RFLPs, AFLPs, and SSRs and their use for predicting progeny variance. Crop Sci. 39:228-237.

Cregan, P.B., T. Jarvik, A.L. Bush, R.C. Shoemaker, K.G. Lark, A.L. Kahler, N. Kaya, T.T. vanToai, D.G. Lohnes, J. Chung, and J.E. Specht. 1999. An integrated genetic linkage map of the soybean genome. Crop Sci. 39:1464-1490.

Field, D. and C. Wills. 1996. Long, polymorphic microsatellites in simple organisms. Proc. R. Soc. Lond. B. Biol. Sci. 263:209-215.

Fischer, D. and K. Bachmann. 1998. Microsatellite enrichment in organisms with large genomes (Allium cepa L.). Biotechniques 24:796-802.

Fischer, D. and K. Bachmann. 2000. Onion microsatellites for germplasm analysis and their use in assessing intra- and interspecific relatedness within the subgenus Rhizirideum. Theor. Appl. Genet. 101:153-164.

Gupta, P.K. and R.K. Varshney. 2000. The development and use of microsatellite markers for genetic analysis and plant breeding with emphasis on bread wheat. Euphytica 113:163-185.

Hang, T.T.M., M. Shigyo, N. Yamauchi, and Y. Tashiro 2004. Production and characterization of alien chromosome additions in shallot (Allium cepa L. Aggregatum group) carrying extra chromosome(s) of Japanese bunching onion (A. fistulosum L.). Genes Genet. Syst. 79:263-269.

Jones, C.J., K.J. Edwards, S. Castaglione, M.O. Winfield, F. Sala, C. van deWiel, G. Bredemeijer, B. Vosman, M. Matthes, A. Daly, R. Brettschneider, P. Bettini, M. Buiatti, E. Maestri, A. Malcevschi, N. Marmiroli, R. Aert, G. Volckaert, J. Rueda, R. Linacero, A. Vazquez, and A. Karp. 1997. Reproducibility testing of RAPD, AFLP and SSR markers in plants by a network of European laboratories. Mol. Breed. 3:381-390.

King, J.J., J.M. Bradeen, O. Bark, J.A. McCallum, and M.J. Havey. 1998. Alow-density genetic map of onion reveals a role for tandem duplication in the evolution of an extremely large diploid genome. Theor. Appl. Genet. 96:52-62.

Martin, W.J., J. McCallum, M. Shigyo, J. Jakse, J.C. Kuhl, N. Yamane, M. Pither-Joyce, A.F. Gokce, K.C. Sink, C.D. Town, and M.J. Havey. 2005. Genetic mapping of expressed sequences in onion and in silico comparisons with rice show scant colinearity. Mol. Gen. Genomics 274:197-204

Morgante, M. and A.M. Olivieri. 1993. PCR-amplified microsatellites as markers in plant genetics. Plant J. 3:175-182.

Powell, W., M. Morgante, C. Andre, M. Hanafey, J. Vogel, S. Tingey, and A. Rafalski. 1996. The comparison of RFLP, RAPD, AFLP and SSR (microsatellite) markers for germplasm analysis. Mol. Breed. 2:225-238.

Röder, M.S., V. Korzun, K. Wendehake, J. Plaschke, M.H. Tixier, P. Leroy, and M.W. Ganal. 1998. A microsatellite map of wheat. Genetics 149:2007-2023.

Russell, J.R., J.D. Fuller, M. Macaulay, B.G. Hatz, A. Jahoor, W. Powell, and R. Waugh. 1997. 
Direct comparison of levels of genetic variation among barley accessions detected by RFLPs, AFLPs, SSRs and RAPDs. Theor. Appl. Genet. 95:714-722.

Schlötterer, C. and D. Tautz. 1992. Slippage synthesis of simple sequence DNA. Nucleic Acids Res. 20:211-215.

Shigyo, M., Y. Tashiro, S. Isshiki, and S. Miyazaki. 1996. Establishment of a series of alien monosomic addition lines of Japanese bunching onion (Allium fistulosum L.) with extra chromosomes from shallot (A. cepa L. Aggregatum group). Genes Genet. Syst. 71:363-371.

Somers, D.J., P. Isaac, and K. Edwards. 2004. A high-density microsatellite consensus map for bread wheat (Triticum aestivum L.). Theor. Appl. Genet. 109:1105-1114.

Song, Y.S., K. Suwabe, T. Wako, T. Ohara, T. Nunome, and A. Kojima. 2004. Development of microsatellite markers in bunching onion(Allium fistulosum L.). Breed. Sci. 54:361-365.

Tautz, D. 1989. Hypervariability of simple sequences as a general source for polymorphic DNA markers. Nucleic Acids Res. 17:6463-6471.

Tautz, D. and M. Renz. 1984. Simple sequences are ubiquitous repetitive components of eukaryotic genomes. Nucleic Acids Res. 12:4127-4138.

Toth, G., Z. Gaspari, and J. Jurka. 2000. Microsatel- lites in different eukaryotic genomes: Survey and analysis. Genome Res. 10:967-981.

van Heusden,A.W., J.W. van Ooijen, R. Vrielink-van Ginkel, W.H.J. Verbeek, W.A. Wietsma, and C. Kik. 2000a. A genetic map of an interspecific cross in Allium based on amplified fragment length polymorphism (AFLP $\left.{ }^{\mathrm{TM}}\right)$ markers. Theor. Appl. Genet. 100:118-126.

van Heusden, A.W., M. Shigyo, Y. Tashiro, R. Vrielink-van Ginkel, and C. Kik. 2000b. AFLP linkage group assignment to the chromosomes of Allium cepa L. via monosomic addition lines. Theor. Appl. Genet. 100:480-486. 